\title{
Video Article \\ Measuring Sub-23 Nanometer Real Driving Particle Number Emissions Using the Portable DownToTen Sampling System
}

\author{
Markus Bainschab ${ }^{1}$, Lukas Landl ${ }^{2}$, Jon Andersson ${ }^{3}$, Athanasios Mamakos ${ }^{4}$, Stefan Hausberger ${ }^{2}$, Alexander Bergmann ${ }^{1}$ \\ ${ }^{1}$ Institute of Electrical Measurement and Sensor Systems, Graz University of Technology \\ ${ }^{2}$ Institute of Internal Combustion Engines and Thermodynamic, Graz University of Technology \\ ${ }^{3}$ Ricardo UK Ltd. \\ ${ }^{4} \mathrm{AVL}$ List $\mathrm{GmbH}$
}

Correspondence to: Markus Bainschab at m.bainschab@tugraz.at

URL: https://www.jove.com/video/61287

DOI: doi:10.3791/61287

Keywords: Engineering, Issue 159, automotive, emissions, particle number, sub-23 nm, portable emission measurement, real driving emissions, sampling, dilution

Date Published: 5/22/2020

Citation: Bainschab, M., Landl, L., Andersson, J., Mamakos, A., Hausberger, S., Bergmann, A. Measuring Sub-23 Nanometer Real Driving Particle Number Emissions Using the Portable DownToTen Sampling System. J. Vis. Exp. (159), e61287, doi:10.3791/61287 (2020).

\section{Abstract}

The current particle size threshold of the European Particle Number (PN) emission standards is $23 \mathrm{~nm}$. This threshold could change because future combustion engine vehicle technology may emit large amounts of sub-23 nm particles. The Horizon 2020 funded project DownToTen (DTT) developed a sampling and measurement method to characterize particle emissions in this currently unregulated size range. A PN measurement system was developed based on an extensive review of the literature and laboratory experiments testing a variety of PN measurement and sampling approaches. The measurement system developed is characterized by high particle penetration and versatility, which enables the assessment of primary particles, delayed primary particles, and secondary aerosols, starting from a few nanometers in diameter. This paper provides instruction on how to install and operate this Portable Emission Measurement System (PEMS) for Real Drive Emissions (RDE) measurements and assess particle number emissions below the current legislative limit of $23 \mathrm{~nm}$.

Introduction

The Particle Measurement Programme (PMP) was founded by the UK Government for the "development of type approval test protocols for assessing vehicles fitted with advanced particulate reduction technology that would complement or replace current legislative measurement procedures"1. The PMP is the world's first particle number-based emissions regulation, targeted specifically at carbonaceous particles $\geq 23 \mathrm{~nm}$. Recent measurements indicate that it may be necessary to include smaller particles.

Negative health impacts of diesel soot are well understood ${ }^{2}$, and therefore, the 'precautionary principle' was invoked on the basis that the elimination of carbon particles from diesel exhaust, via the mandatory use of diesel particulate filters (DPFs), was imperative on health grounds. However, because in European legislation a limit value must force adoption of emissions control technologies, this could not be achieved without an appropriate measurement method. With strong political backing across Europe, the UK Government led the conception of the PMP to improve particulate measurements. The PMP, under the auspices of the United Nations Economic Commission for Europe (UN-ECE) ${ }^{3}$, included the expertise of others from around the globe. Two particle research projects were completed in 2001. One of them (Particulate Research ${ }^{4}$ ) was carried out by the UK Government Department of the Environment, Transport and the Regions (DETR), in partnership with the Society of Motor Manufacturers and Traders (SMMT) and the Oil Companies European Organisation for Environment, Health and Safety (CONCAWE). The other one (PARTICULATES ${ }^{5}$ ) was funded by the European Union's $5^{\text {th }}$ Framework and was carried out by 14 different European partners. The results of both projects indicated that particle number-based procedures were promising, but that challenges for repeatable and reproducible measurements remained.

In 2007 the final report of the PMP Light-duty Inter-laboratory Correlation Exercise was published ${ }^{6}$, including some improvements on the filterbased mass measurement method, primarily demonstrating the feasibility of a number count-based method for regulatory purposes based upon a defined particle size range and particle volatility. Both methods were implemented based upon sampling from the existing constant volume sampler (CVS) dilution tunnel approach originally developed for particulate matter mass and bagged dilute gaseous emissions measurements.

Within the number count-based method, a lower particle size limit of $\sim 20 \mathrm{~nm}$ was selected. The primary objective of the project was to ensure particles of this size and above were controlled by legislation. It is now known that the primary particle size in engine exhaust can be $<20 \mathrm{~nm}^{7,8,9}$. For practical reasons, a particle counter with a $50 \%$ counting efficiency $\left(d_{50}\right)$ at $23 \mathrm{~nm}$ was selected, and this size became the accepted lower size threshold. It was recognized that due to the high sensitivity to properties such as dilution, air temperature, humidity, and ratio ${ }^{10}$, volatile particle size distribution and integrated number measurements could be repeatable in one CVS-equipped facility with one vehicle, but much less so from facility to facility. Thus, for rigorous regulations, it was necessary to focus purely on nonvolatile particles, with the measurement approach effectively defining the regulatory particle boundary conditions on size and volatility. European diesel fuel has back-end volatility such that only a few percent boils at temperatures above $350^{\circ} \mathrm{C}$, and early work within the PMP indicated that short residence times at this temperature were suitable for the complete evaporation of tetracontane, a linear hydrocarbon containing 40 carbon atoms with volatility towards the end boiling 
point of engine lubricant ${ }^{11}$. Consequently, a temperature of $350^{\circ} \mathrm{C}$ has become the de facto reference point for regulatory $>23 \mathrm{~nm}$ particle volatility.

The PMP measurement system specification comprises components for sampling, sample conditioning, and measurement, summarized in Table 1.

\begin{tabular}{|l|l|l|}
\hline Stage & Identity & Purpose \\
\hline $\mathbf{0}$ & Sample source & Origin of sample \\
\hline $\mathbf{1}$ & Particle Transport & $\begin{array}{l}\text { Conduct sample from origin to measurement } \\
\text { system }\end{array}$ \\
\hline $\mathbf{2}$ & Volatile Particle Remover & $\begin{array}{l}\text { Eliminate volatiles and define non-volatile } \\
\text { particles to be measured }\end{array}$ \\
\hline $\mathbf{3}$ & Particle Number Counter & $\begin{array}{l}\text { Enumerate non-volatile particles and define the } \\
\text { lower size limit }\end{array}$ \\
\hline
\end{tabular}

Table 1: Elements of the PMP Measurement System.

The European PMP PN approach is being implemented and now applies to light-duty diesel (September 2011, EURO 5b) and GDI vehicles (September 2014, EURO 6), and to diesel and gas heavy-duty engines (February 2013, EURO VI).

Recent measurements showed that some light-duty vehicles and, in particular, spark ignition technologies, can emit substantial levels of particles $<23 \mathrm{~nm}^{12,13,14}$. This led the European Commission to fund research projects to develop new or extended methods that can be rapidly implemented as a replacement, or addition to, the current $>23 \mathrm{~nm}$ regulation.

One such project, DownToTen (DTT), aims to preserve the general approach of PMP and extend the measurement range down to a $d_{50} \leq 10$ $\mathrm{nm}$. To this end, the configuration of the DTT measurement system was designed to include the same basic elements described in Table 1, but with the conditioning and measurement steps optimized to enable efficient transport and detection of the $<23 \mathrm{~nm}$ particles. The DTT system was initially developed for laboratory use but was modified to operate as a portable emissions measurement system (PEMS). For the DTT PNPEMS system, the components were optimized to reduce weight and power consumption and increase physical robustness without substantially diverging from the original design. For mobile application, the system must be resistant to harsher and erratic temperatures, pressures, and vibration environments likely encountered in light- and heavy-duty PEMS testing. The impact of pressure variations at the inlet of the system was modelled and studied experimentally ${ }^{15}$. The resistance to vibrations was assessed using a dedicated test bed ${ }^{16}$. Vibrations and accelerations that occur during typical RDE drives did not impair the measurement results of the condensation particle counters used. The DTT system is also designed for use at low temperatures, where the volatile removal function is inactive, to feed an aging chamber and study secondary organic aerosol formation ${ }^{17}$.

The thermal conditioning elements of the DTT measurement system that define the regulatory volatility boundary of particles closely parallel the elements of the PMP system in that both systems contain the sequence:

1. First particle number dilution stage

2. $\mathrm{HC} /$ volatile elimination stage

3. Second particle number dilution stage

The primary differences between the DTT and PMP systems are that the DTT system components are selected to:

1. Maximize transmission of $\sim 10 \mathrm{~nm}$ PN from the sample source to the particle counter using low loss dilution and particle transmission approaches

2. Comprehensively remove volatiles using oxidative particle elimination rather than merely reducing partial pressures of condensable $\mathrm{HC}$ species through evaporation and dilution

3. Count particles of $\sim 10-50 \mathrm{~nm}$ with greater efficiency than current PMP systems

The objective of this paper is to present the use of the DTT PN-PEMS system for measuring nonvolatile particles $\geq 10 \mathrm{~nm}$ from an in-use road vehicle. This includes an introduction to the measurement system and its main components, performing laboratory-based calibration measurements, installing the device for a mobile application, conducting a real driving emission measurement, and processing the collected measurement data.

\section{Instrumentation}

The DTT PN-PEMS was designed to provide high particle penetration down to a few nanometers, robust particle number dilution, removal of volatile particles, and prevention of artificial particle formation. The components of the system were selected based on results from laboratory experiments comparing a variety of technologies for dilution and aerosol conditioning. This section provides an overview of the system, its working principle, and the components used. Figure 1 shows a schematic of the system. Figure 2 shows a photo of the system. The DTT system is $60 \mathrm{~cm}$ high and has a footprint of $50 \mathrm{~cm} \times 50 \mathrm{~cm}$. The weight of the system is approximately $20 \mathrm{~kg}$. Including the required peripheral elements (i.e., battery and gas bottle) the total weight is approximately $80 \mathrm{~kg}$. The major elements of the system are the two dilution stages (i.e., first hot, second cold), a catalytic stripper, and at least one condensation particle counter (CPC). 


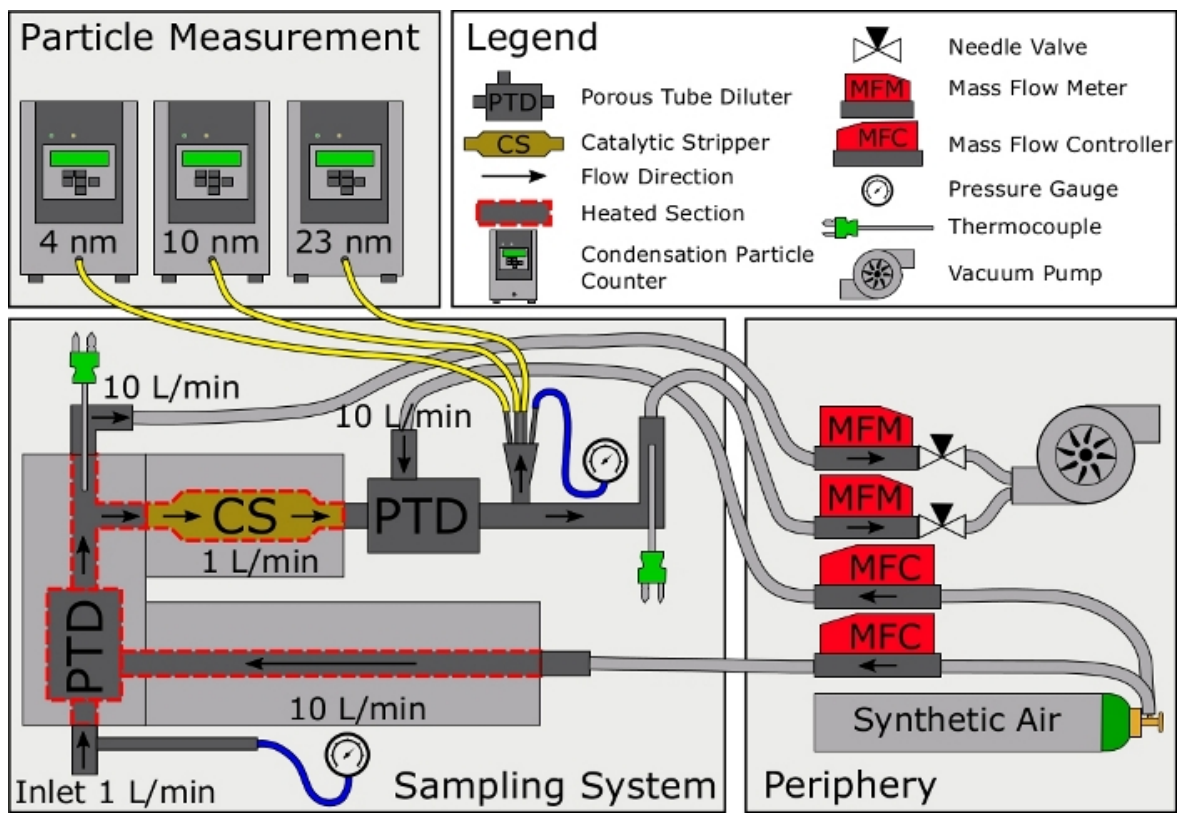

Figure 1: Schematic drawing of the DTT particle number portable emission measurement system. Please click here to view a larger version of this figure.

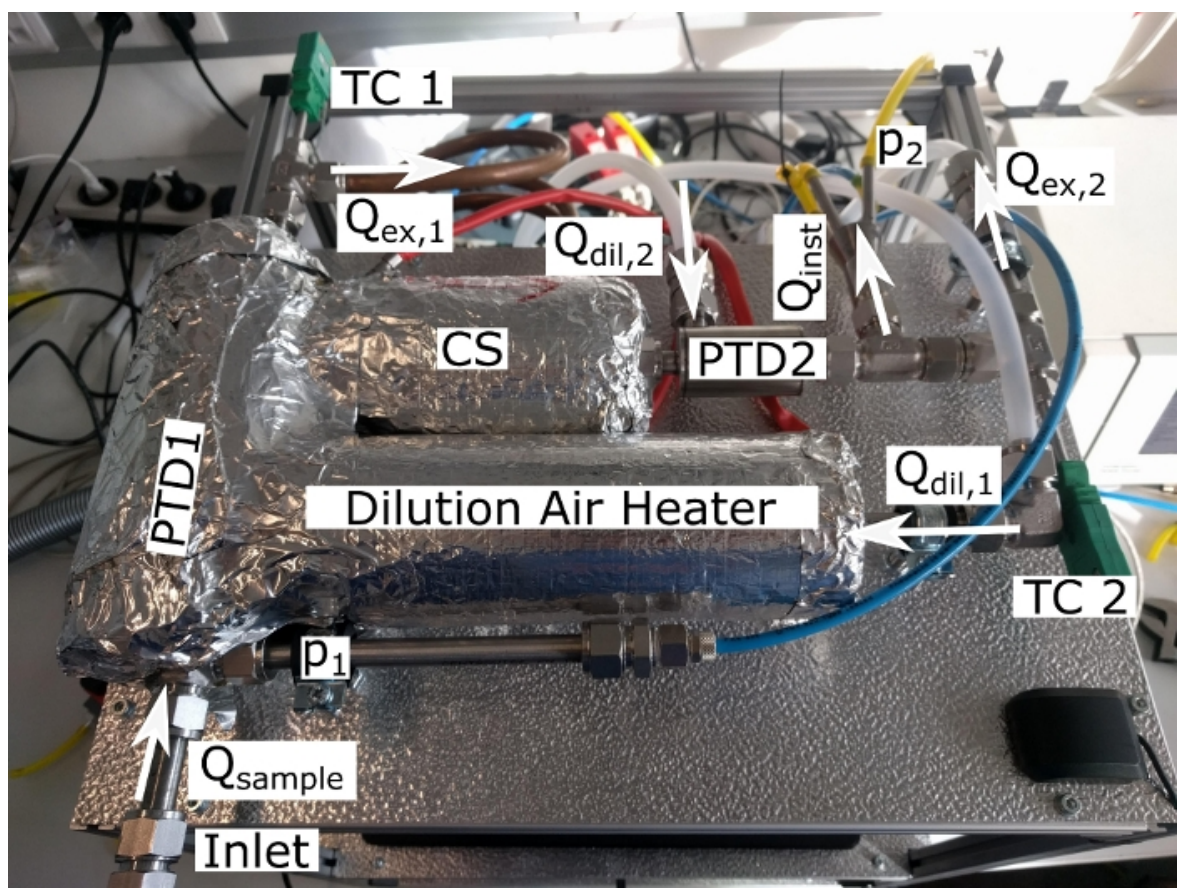

Figure 2: Top view picture of the DTT sampling system. Please click here to view a larger version of this figure.

Two dilution stages reduce the particle number concentrations to levels measurable by condensation particle counters $\left(<10^{4} \# / \mathrm{cm}^{3}\right)$. Custommade porous tube diluters are used for both dilution stages. This technology was selected because of its low particle loss ${ }^{18,19}$. The radial ingress of dilution air convectively keeps particles away from the walls, which reduces particle losses. Furthermore, these diluters can be very small and can withstand temperatures of $400^{\circ} \mathrm{C}$. The porous material used is a sintered hastalloy X tube (GKN Filters Metals GmbH, Radevormwald, Germany). Static mixing elements inside the porous tube provide a well-mixed aerosol directly downstream of the diluter. This allows taking a representative sample of the diluted aerosol for further conditioning or measurement by splitting the aerosol flow directly downstream of the diluter, and allows for a compact sampling system. The primary dilution stage is typically heated to $350{ }^{\circ} \mathrm{C}$, while the second stage is operated at ambient temperature. The dilution factor of the system is approximately 80 . The exact value is dependent on the inlet flow and the mass flow management: The flow rates in the sampling system are managed by a system of two mass flow controllers and two mass flow meters. The mass flow controllers control the dilution air flow rates. The mass flow meters monitor the flow rates extracted downstream of dilution stages 1 and 2. The differences between the flows extracted and the flows supplied can be changed. In other words, the net flow added or subtracted in one dilution stage can be defined. The sample flow rate, $Q_{\text {sample, }}$, is defined as the sum of all other flow rates: 1) Flow rate drawn by the 
measurement instruments $\left.\left(Q_{i n s t}\right) ; 2\right)$ the dilution air flow rates $\left(Q_{\mathrm{dil}, \mathrm{i}}\right)$; and 3$)$ the excess flow rates $Q_{\mathrm{ex}, \mathrm{i}}$. For the calculation of the sample flow, the contributions of the flows extracted from the system are positive and the contributions of the flows fed into the system are negative.

$Q_{\text {sample }}=Q_{e x, 1}+Q_{e x, 2}+Q_{\text {inst }}-Q_{\text {dil, } 1}-Q_{\text {dil, }}$

The total dilution ratio $D R$ is calculated by:

$D R=D R_{1} \times D R_{2}=\left(\frac{Q_{\text {dfl,1 }}}{Q_{\text {sample }}}+1\right) \times\left(\frac{Q_{\text {dil }, 2}}{Q_{\text {sample }}+Q_{\text {dil }, 1}-Q_{\text {ex }, 1}}+1\right)$

A catalytic stripper (CS) is situated between dilution stage 1 and 2 and is operated at $350{ }^{\circ} \mathrm{C}$ at a flow rate of 1 liter per minute (L/min). The catalytic stripper provides oxidation of organic compounds and sulphur storage. The removal of these substances ensures the isolation of the solid particle fraction. The undesired formation of volatile and semivolatile particles and growth of subcut size particles is prevented. The catalytic stripper used is commercially available (AVL GmbH). The volatile particle removal efficiency of the CS was verified with polydisperse emery oil particles $>50 \mathrm{~nm}$ and $>1 \mathrm{mg} / \mathrm{m}^{3}\left(3.5-5.5 \mathrm{mg} / \mathrm{m}^{3}\right.$ ) showing an efficiency of $>99 \%$ (actual value $99.9 \%$ ) as defined by RDE regulations ${ }^{20}$. This is a more rigorous test than the tetracontane test prescribed in the current PMP protocol.

One or more condensation particle counters are used to measure the particle number concentration downstream of the second dilution stage. A CPC with $a d_{50}$ of $23 \mathrm{~nm}$ enables the measurement of the currently regulated emission of solid particles larger than $23 \mathrm{~nm}$. Additionally, measuring the particle number concentration with one or more CPCs with a lower $d_{50}$ cut point (e.g., $10 \mathrm{~nm}, 4 \mathrm{~nm}$ ) enables the assessment of the currently unregulated solid particle fraction $<23 \mathrm{~nm}$ down to the $d_{50}$ cut size of the applied CPC.

The dilution air supply line, the primary porous tube diluter, and the catalytic stripper have independent heating elements containing k-type thermocouples (TC). Independently heating different sections controls the temperature distribution in the system.

In addition to the thermocouples in the heating elements, two thermocouples are placed downstream of dilution stage 1 and 2 . These two thermocouples directly measure the aerosol temperature.

Two absolute pressure sensors (NXP MPX5100AP) are used to monitor the pressure at the inlet and the outlet of the sampling system.

For mobile measurements, a Clayton Power LPS 1500 battery pack is used. A 10 L synthetic air bottle supplies the system with dilution air during mobile applications. The sizes of the battery and the gas bottle are chosen so that the system can operate independently for 100 min.

The system is controlled via a NI myRIO running a LabVIEW virtual instrument. The virtual instrument allows for control of the flow rates and heater temperatures. Apart from the controlled parameters, the aerosol temperatures, pressures, and acceleration (via the sensor integrated in myRIO) can be monitored and logged. A myRIO accessory GPS module enables logging of the position data. Figure $\mathbf{3}$ and Figure $\mathbf{4}$ show the user interface of the virtual instrument used for controlling the DTT system.

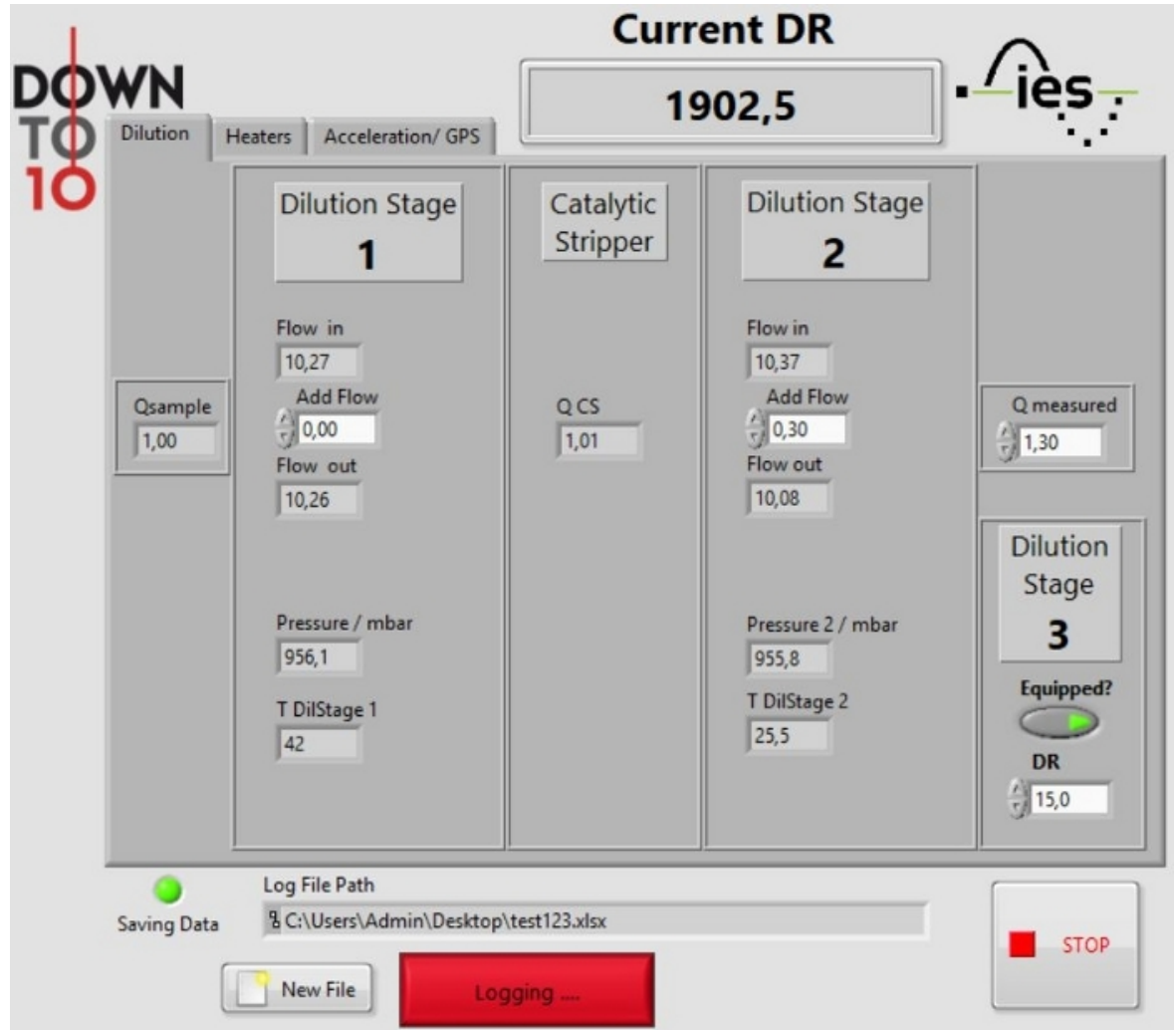

Figure 3: DTT virtual instrument dilution stage parameter overview. Please click here to view a larger version of this figure. 


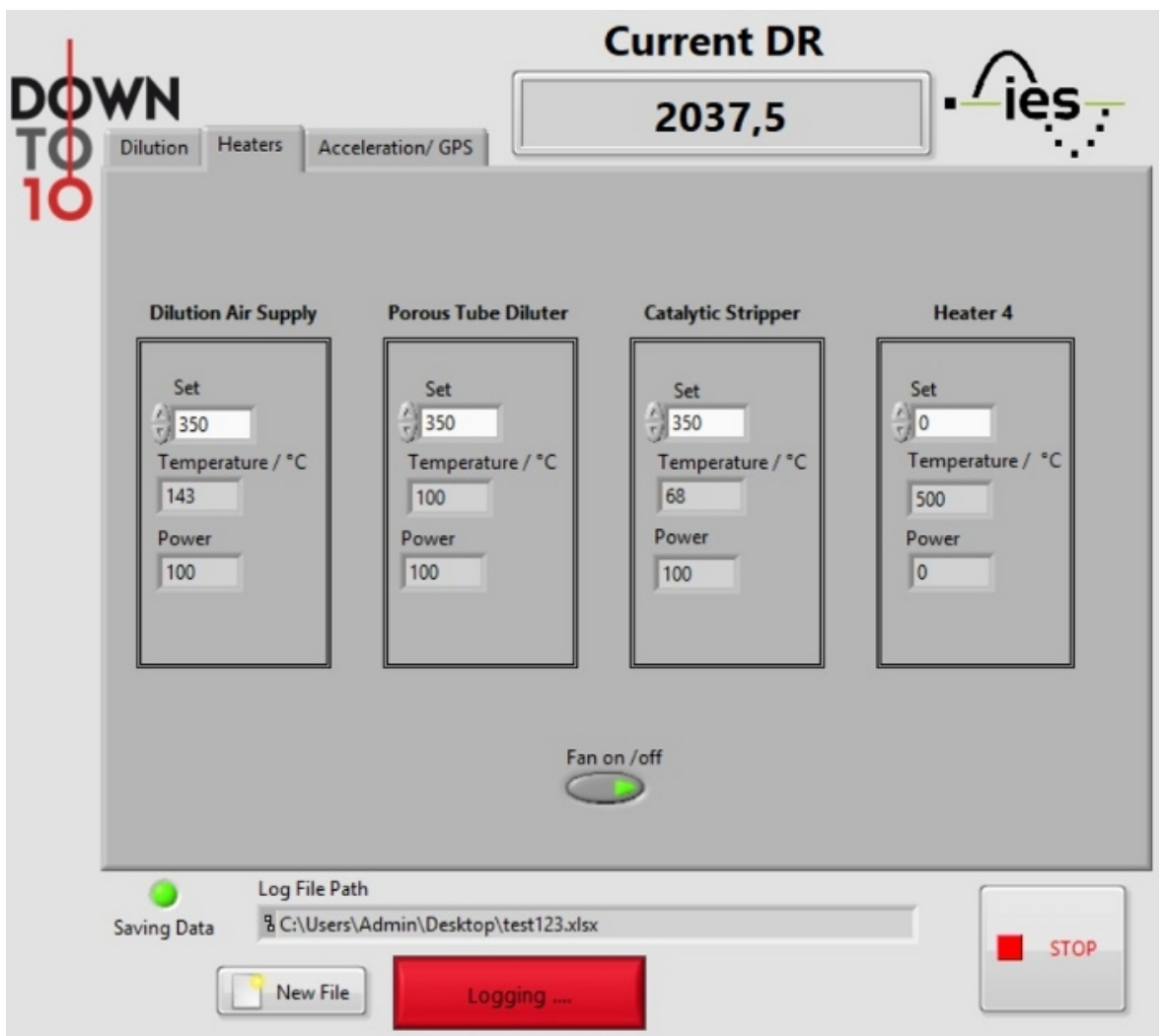

Figure 4: DTT virtual instrument heater control panel. Please click here to view a larger version of this figure.

Any kind of sampling procedure causes particle losses. To be able to account for these losses, laboratory measurements are performed to determine the particle size dependent particle penetration through the DTT sampling system. In these measurements, the particle concentration of monodisperse aerosol is measured upstream and downstream of the sampling system using two condensation particle counters. Figure 5 shows the experimental setup for the calibration measurements. In this setup, a Jing miniCAST is used as a particle source ${ }^{21,22}$. Mass flow controllers (MFC) are used to control the gas flows into the burner. A dilution bridge enables the adjustment of the particle number concentration. The dilution bridge is a high-efficiency particulate air (HEPA) filter parallel to a needle valve. Adjusting the position of the needle valve alters the dilution ratio by changing the ratio between the fraction of the aerosol passing through the HEPA filter and the fraction of the aerosol passing through the needle valve. The filtered and the unfiltered aerosols are recombined with a T-piece to form a diluted aerosol. A catalytic stripper is used to remove possibly abundant volatile compounds generated as byproducts of the combustion process. A TSI 3082 electrostatic classifier together with a TSI 3085 differential mobility analyzer (nano DMA) are used for the size selection of particles. Two TSI CPCs $3775\left(d_{50}=4 \mathrm{~nm}\right)$ are used to measure the particle number concentration upstream and downstream of the DTT sampling system. The counters' cut point of $d_{50}=$ $4 \mathrm{~nm}$ allows for the penetration determination at particle sizes as low as $10 \mathrm{~nm}$ and below.

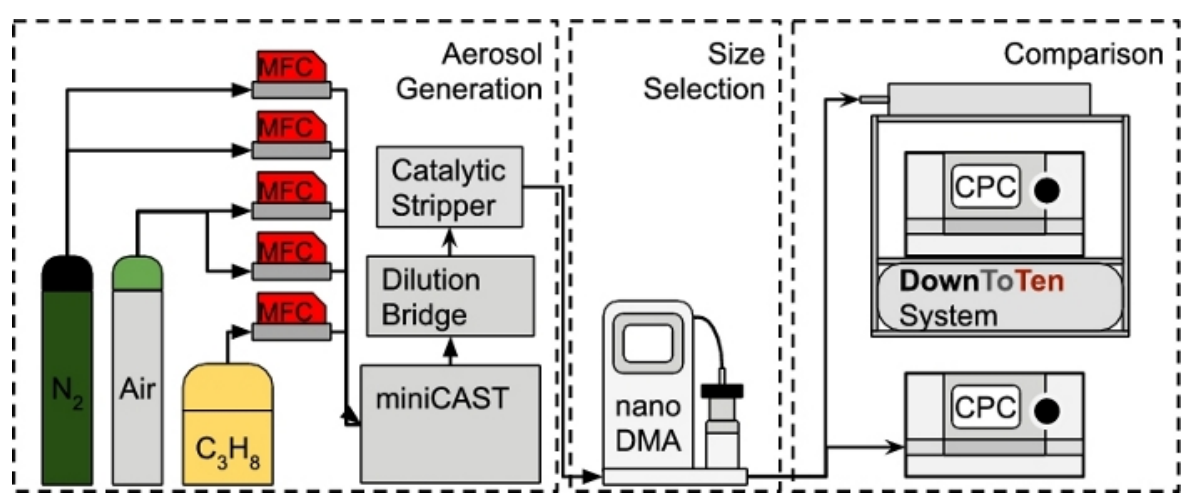

Figure 5: Schematic drawing of the experimental setup used for the calibration of the DTT sampling system. Please click here to view a larger version of this figure. 


\section{Protocol}

\section{Calibration procedure}

1. Set up and prepare instruments.

1. Place the instruments described, shown in Figure 5, in an organized and compact way in a laboratory with an extraction system.

2. Connect the instruments as indicated by the arrows in Figure $\mathbf{5}$ using conductive tubing. Keep the tubing as short as possible to minimize diffusional particle losses.

3. Connect the instruments requiring power (i.e., DTT system, DTT system pump, two CPCs, DMA, catalytic stripper, and MFCs) to sockets.

4. Connect the CPCs, the DTT system, and the MFC to a laptop.

5. Make sure the laptop has the required software installed to communicate with the connected devices.

6. Install missing software if required.

2. Warm up experimental components at least 30 minutes before starting the calibration measurements to ensure a thermally stable measurement setup.

1. Start the operation of the burner by setting the gas flow controlled by the external MFC to the start setting specified in the user's manual.

2. Ignite the flame.

3. Feed the generated soot into the extraction system.

4. Produce soot particles with a mean diameter of $50 \pm 5 \mathrm{~nm}$ by setting the MFC-controlled flows accordingly. A table of settings and expected particle size distribution can be found in the burner manual or in the literature ${ }^{23}$. For the miniCAST settings in Table 2 can be used:

5. Start heating the catalytic stripper by setting the corresponding temperature controller to $350{ }^{\circ} \mathrm{C}$.

6. Switch on the CPCs and set to low flow mode (i.e., inlet flow of $0.3 \mathrm{~L} / \mathrm{min}$ ).

7. Set up the communication of the CPCs with the laptop using the CPCs manufacturer's software or serial communication.

8. Start up the DTT system warm up procedure as described in section 3.1.

9. Install the impactor with a $0.071 \mathrm{~cm}$ nozzle at the inlet of the classifier according to the user's manual.

10. Switch on the classifier. The display on the classifier should show an impactor flow of $1.30 \pm 0.05 \mathrm{~L} / \mathrm{min}$. If the flow shown is different, double check the tubing connecting the classifier with the CPC and the DTT system.

11. Set the sheath flow rate of the classifier to $13 \mathrm{~L} / \mathrm{min}$ using the user interface.

12. If a soft X-ray source (TSI 3088) is used, switch on the classifier's neutralizer.

\begin{tabular}{|l|l|}
\hline Gas & Flow rate \\
\hline Propane & $20 \mathrm{~mL} / \mathrm{min}$ \\
\hline Quench gas $\left(\mathrm{N}_{2}\right)$ & $2 \mathrm{~L} / \mathrm{min}$ \\
\hline Dilution air & $5 \mathrm{~L} / \mathrm{min}$ \\
\hline Oxidation air & $0.5 \mathrm{~L} / \mathrm{min}$ \\
\hline Mixing gas $\left(\mathrm{N}_{2}\right)$ & $0 \mathrm{~L} / \mathrm{min}$ \\
\hline
\end{tabular}

Table 2: Suggested miniCAST flow rates for calibration measurements.

3. After at least $30 \mathrm{~min}$ of warm up time perform the calibration measurements.

1. Stop feeding the generated soot into the extraction system and connect the outlet of the burner to the dilution bridge.

2. Set the particle size selected by the classifier to $10 \mathrm{~nm}$ using the user interface.

3. Using the dilution bridge needle valve, adjust the particle number concentration upstream of the DTT system to be $10^{4} \pm 10^{3} \# / \mathrm{cm}^{3}$. This particle concentration yields a relatively high signal, enabling short measurement times while the CPCs operate in single-count mode, which ensures high accuracy. If the desired concentration of $10^{4} \pm 10^{3} \mathrm{\#} / \mathrm{cm}^{3}$ cannot be reached because of exceedingly low particle concentrations emitted by the soot generator, maximize the throughput through the dilution bridge by fully opening the valve.

4. Start logging the data of the DTT system (if not started already) by clicking the "Start Data Logging" button in the DTT Labview software.

5. Start logging the data of the two CPCs using the proprietary software or serial communication.

6. Wait $30 \mathrm{~s}$ for the experimental setup to stabilize.

7. Note down a timestamp and the set particle size to mark the start of the measurement.

8. Run the measurement for 2 min.

9. Note down a timestamp to mark the end of the measurement.

10. Repeat steps 1.3.3-1.3.9 for particle sizes of $15 \mathrm{~nm}, 30 \mathrm{~nm}, 50 \mathrm{~nm}$, and $100 \mathrm{~nm}$. Additional measurements can be taken if better size resolution is desired.

11. Perform another set of measurements at the same particle sizes as before by repeating steps 1.3.2-1.3.10.

12. Stop logging the measurement data of the two CPCs and the DTT system.

13. Shut down all the instruments.

4. Evaluate the collected calibration data with a spreadsheet program.

1. Export the particle concentration data measured by the CPCs into a .csv or .txt file. 
2. Import the CPC and the DTT system data into a data evaluation tool.

3. Assign the data to the corresponding measurements by allocating data from each instrument (i.e., 2 CPCs, DTT system) with a timestamp between the start and the end timestamp of a measurement to the corresponding measurement. It is recommended to automate this task with a data evaluation tool.

4. Time average the two particle concentration datasets (CPCs) and the dilution ratio (DTT system) for all measurement points.

5. Calculate the relative particle penetration for all measurement points according to the following formula:

$P_{n}=\frac{C_{d, n}^{\prime}}{C_{u, n}} D^{\prime} R_{n}$

Where $P_{\mathrm{n}}$ is the relative particle penetration at a certain measurement point $n . C_{d, n}^{\prime}$ is the particle concentration measured by the CPC downstream of the DTT system averaged over the timespan of the measurement point $n$. $C_{u, n}^{\prime}$ is the corresponding particle concentration measured by the CPC upstream of the DTT system averaged over the timespan of the measurement point $n$. D $R_{n}$ is the dilution ratio from the DTT system, averaged over the timespan of the measurement point $n$.

6. Calculate the mean particle penetration $P_{\text {mean }}$ by averaging over the average particle penetrations at $30 \mathrm{~nm}, 50 \mathrm{~nm}$, and $100 \mathrm{~nm}$ particle size.

$P_{\text {mean }}=\frac{P_{30 \mathrm{~nm}}+P_{50 \mathrm{~mm}}+P_{100 \mathrm{~nm}}}{3}$

This value is used for the calculation of the Particle Concentration Reduction Factor (PCRF) dividing the dilution ratio $D R$ with the mean penetration efficiency $P_{\text {mean }}$.

$P C R F=\frac{D R}{P_{\text {mean }}}$

The PCRF is calculated from the penetration at $30 \mathrm{~nm}, 50 \mathrm{~nm}$, and $100 \mathrm{~nm}$ to be comparable with PMP compliant, commercially available instruments. The measurements at sizes other than $30 \mathrm{~nm}, 50 \mathrm{~nm}$, and $100 \mathrm{~nm}$ are used to determine the $d_{50}$ cutoff size of the system to better characterize the system outside the regulatory frame.

\section{Installation and preparation for real driving emissions measurements}

1. Select a vehicle to assess for particle number emissions for particles $<23 \mathrm{~nm}$.

2. Select a route to measure the particle number emissions of the selected vehicle. There are guides on how to select appropriate routes in the literature ${ }^{24}$.

3. Exhaust flow meter (EFM) installation

1. Choose an EFM with a measurement range matching the expected exhaust flow range of the vehicle to be measured ${ }^{24}$.

2. Place the EFM control box in the trunk of the vehicle.

3. Install the EFM outside of the car, according to the manufacturer's specification sheet. Figure 6 shows an example of an installed EFM, mounted externally on shaped pipes leading into the trunk.

4. Make sure the distance upstream and downstream of the EFM comply with EU regulations (i.e., $4 \mathrm{x}$ the pipe diameter or $150 \mathrm{~mm}$ straight pipe, whichever is larger, should be upstream and downstream of the flow sensor).

5. When measuring vehicles with multiple exhaust manifolds, the individual exhaust pipes should be joined in front of the EFM and the cross-sectional area of this pipe increased accordingly to keep the increase in exhaust backpressure as low as possible. If this is not possible, the exhaust mass flow can be measured with several EFMs.

6. Make sure the connectors from the EFM pipe to the exhaust pipe of the vehicle can withstand the exhaust gas temperatures (i.e., no plastic should be used).

7. The pipe diameter, the connector diameter, and the diameter of any extensions required for sampling should not be smaller than the diameter of the exhaust pipe to keep the exhaust back pressure as low as possible.

8. Start the piping at the exhaust of the vehicle.

9. Connect the exhaust to the first pipe with connecting pipes and pipe clamps. Tighten the pipe clamps only at the end in order to be able to align the pipes during fitting.

10. Connect one pipe at a time with connecting pipes and pipe clamps until there is a connection from the exhaust to the EFM. This should be as short as possible.

11. Place the EFM control box and the EFM mounting bracket in the trunk to ensure that nothing slips during the measurement trip.

12. Check that all the piping is tight and nothing comes loose during the measurement trip.

13. Switch on the EFM.

14. After a warm up time of up to 15 min depending on ambient temperature (see EFM user guide), the exhaust mass flow meter is ready to measure ${ }^{25,26,27,28}$. 


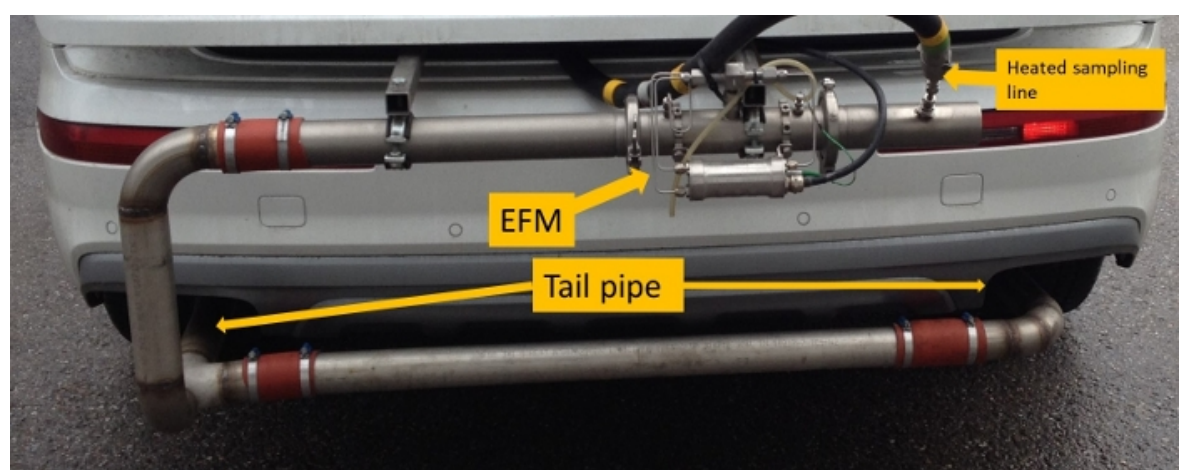

Figure 6: Picture of an installed EFM. Please click here to view a larger version of this figure.

4. Preparing and installing the DTT measurement system in the trunk of the vehicle NOTE: The measurements described here are conducted with two condensation particle counters as counting devices for the DTT system. One of the CPCs (TSI 3790A) has a lower $d_{50}$ cutoff size of $23 \mathrm{~nm}$, which equals the current legislative limit. The other CPC (commercially available $10 \mathrm{~nm}$ AVL CPC) has a lower $d_{50}$ cutoff of $10 \mathrm{~nm}$. Measuring particle emissions with these two instruments in parallel enables the assessment of the currently regulated emissions $(>23 \mathrm{~nm})$ and the $<23 \mathrm{~nm}$ fraction.

1. Take a laptop and install the DTT software and the software for logging the CPC measurement data.

2. Place the synthetic air bottle in the trunk or on the floor in front of the rear seats and fix it using straps.

3. Place the battery in the trunk of the vehicle and fix it. Plug in the AC input cable and connect it to a local power source.

4. Place and fix the vacuum pumps for the sampling system and the condensation particle counters in the trunk of the vehicle and connect them to the battery.

5. Place the DTT system in the trunk of the vehicle and fix its position using straps. Figure 7 and Figure 8 show the DTT system in the trunk of a car. Connect the system to the mobile battery pack.

6. Connect the two inlet MFCs of the DTT system to a stationary pressurized air supply. Connect the two outlet MFMs of the DTT system to the vacuum pump.

7. Use appropriate tubing to drive the exhaust of the pump outside the vehicle.

8. Connect the DTT system to the measurement laptop using a USB cable.

9. Connect the inlet of the system to the sampling point downstream of the EFM. Connect the system power inlet to the battery. Connect the condensation particle counters' power inlets to the battery pack.

10. Connect the CPCs to the respective external vacuum pump.

11. Mount the butanol bottles of the CPCs firmly on the frame of the dilution system as far away as possible from the vehicle occupants.

12. Make sure that the cap is screwed on tight and does not open during the measurement drive when accelerating.

13. Use appropriate tubing to drive the exhaust of the CPCs and/or the external pump outside the vehicle. Connect the CPCs to the measurement laptop using USB cables.

NOTE: Figure 9 shows the prepared vehicle. The DTT system is installed in the trunk of the vehicle. A commercially available PNPEMS system is also installed to use as a reference for the regulated emission of solid particles $>23 \mathrm{~nm}$. 


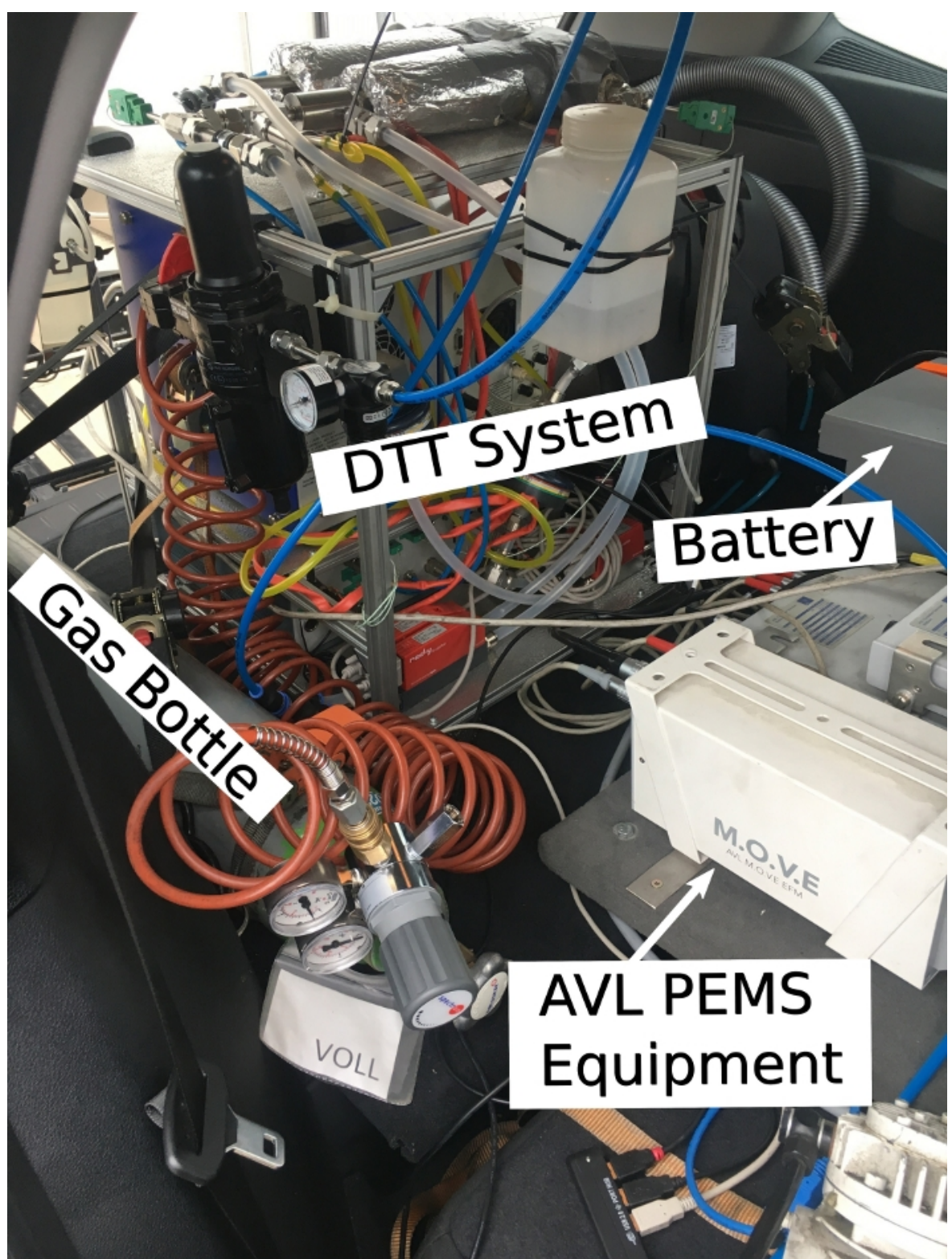

Figure 7: DTT PEMS from inside the vehicle. Please click here to view a larger version of this figure. 


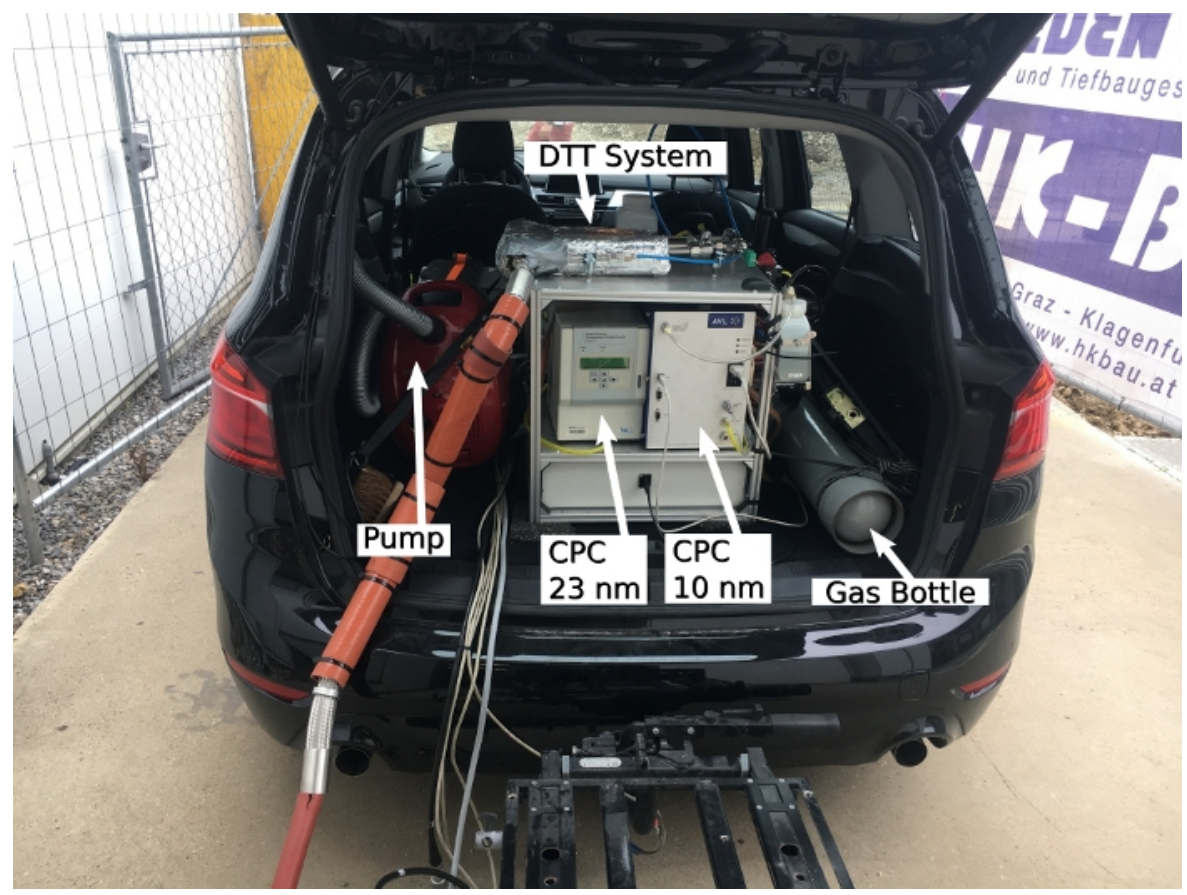

Figure 8: DTT PEMS inside the trunk of a vehicle. Please click here to view a larger version of this figure. 


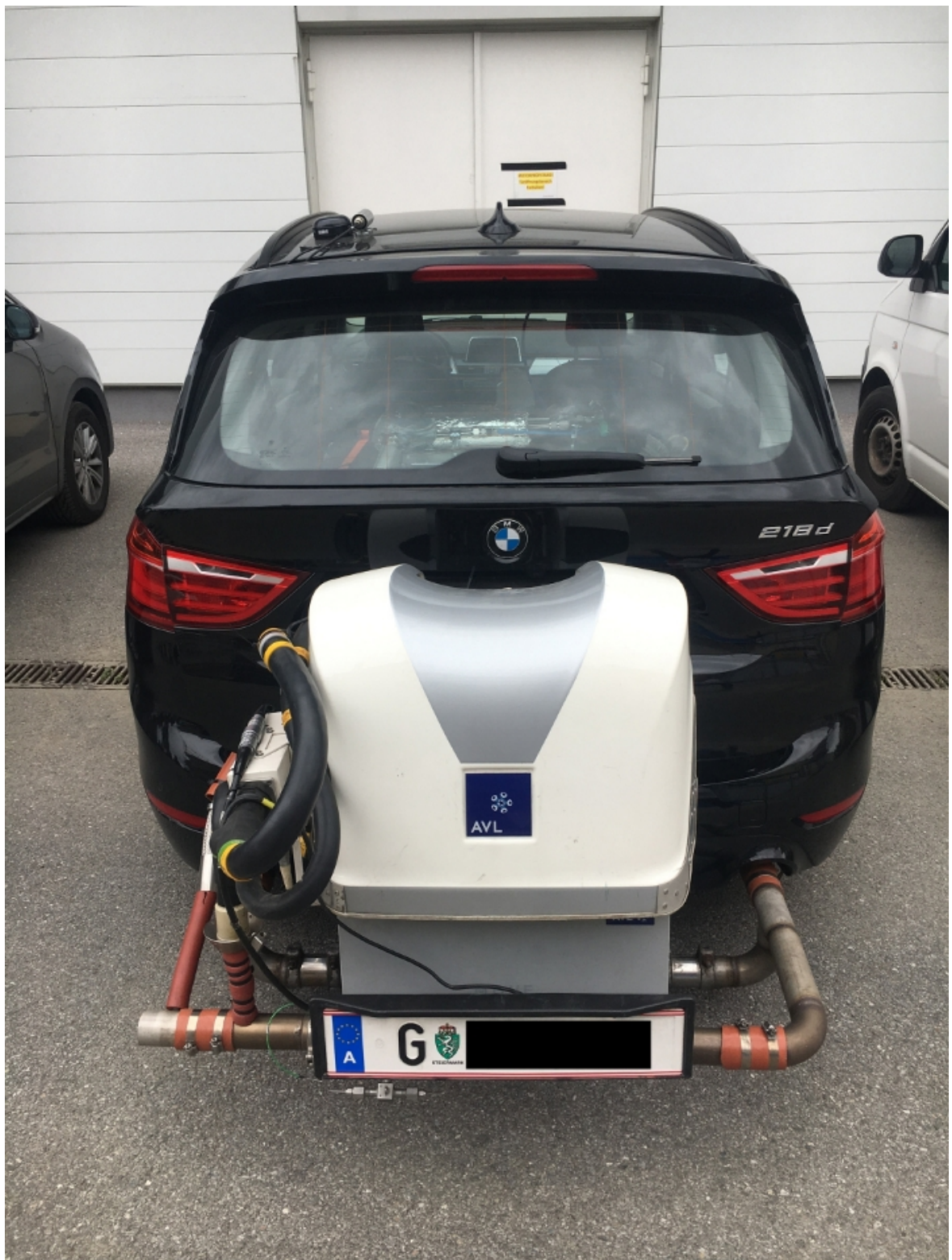

Figure 9: Vehicle with commercially available PN-PEMS (AVL MOVE) and DTT PEMS installed. Please click here to view a larger version of this figure.

\section{Measurement operation}

1. Heating and starting up the measurement system

1. Switch on the two CPCs and their external vacuum supply.

2. Open the CPCs software on the measurement laptop and establish communication with the CPCs. The communication can either run via the instrument's proprietary software or via serial communication as described in the CPC manual.

3. Close the needle valves downstream of the MFMs.

4. Switch on the DTT sampling system pump.

5. Switch on the sampling system by pushing the red switch down.

6. Open the LabVIEW DTT application on the computer. The communication with the system starts automatically.

7. The graphical user interface (GUI) of the DTT LabVIEW application now displays the flows in and out at dilution stages 1 and 2, which should be $0.00 \mathrm{~L} / \mathrm{min}$. If not, double check that the needle valves are closed properly.

8. Enter the mass flow drawn by the connected measurement instruments in $\mathrm{sL} / \mathrm{min}$. If the flow drawn by the instruments is unknown, measure it using a handheld mass flow meter (e.g., Vögtlin red-y compact series). Reconnect the tubing after measuring the flows drawn by the CPCs.

9. Slowly open the needle valves until both "Flows out" reach $10.0 \pm 0.5 \mathrm{sL} / \mathrm{min}$. Both "Flows in" will increase to the same values as the corresponding "Flows out".

10. Adjust the "Add Flow" (i.e., difference between dilution air flow and excess flow) of both dilution stages to get $Q_{C S}=1.0 \pm 0.1 \mathrm{~L} / \mathrm{min}$ through the catalytic stripper and a sample inlet flow of $Q_{\text {sample }}=1.0 \pm 0.1 \mathrm{~L} / \mathrm{min}$. 
11. Click on the "Heater" tab to set the heater temperatures.

12. Set the heater temperatures of the dilution air supply, the first porous tube diluter, and the catalytic stripper to $350{ }^{\circ} \mathrm{C}$. The system will now start to heat up. Below the "Set" interfaces the current temperature and heating power percentages are displayed.

13. Wait until the gas temperature downstream dilution stage 1 ("T DilStage 1" in the GUI) reaches $290^{\circ} \mathrm{C}$ before starting the measurement drive. This will take approximately $20 \mathrm{~min}$.

2. Data logging

1. Start to log the data on the measurement devices connected to the DTT sampling system.

2. Start to log the data of the sampling system by pressing the "Start Data Logging" button and choose a path and a file name in the pop-up window. The log file path will be displayed and the green light will indicate that data are saved. The system data are logged at a frequency of $2 \mathrm{~Hz}$.

3. Log the particle concentration data of the CPC using appropriate software. This can either be the manufacturer's or a serial communication software (e.g., PuTTY).

4. Start logging the exhaust flow with the EFM.

3. Driving

1. Before driving the selected route, disconnect the battery's charging cable and switch from stationary pressurized air supply to the gas bottle.

2. Drive the selected route.

4. After driving

1. Press "Logging ..." to stop recording data. Shut down the instruments.

5. Recharge the battery to prepare for the next drive.

\section{Data analysis}

1. Import the data from the sampling system, the EFM (for exhaust flow), and the measurement devices into the same data analysis program.

2. Perform the time alignment considering the time the exhaust needs to be transported from the tailpipe to the measurement devices. The transport time $t_{\text {dil }}$ through the dilution system is $2.5 \mathrm{~s}$. The transport time $t_{\text {sample }}$ through the sampling line can be calculated as follows:

$t_{\text {sample }}=\frac{A_{\text {sample }} * l_{\text {sample }}}{Q_{\text {sumple }}}$

Where $t_{\text {sample }}$ is the transport time through the sampling line in seconds, $t_{\text {dil }}$ is the transport time through the dilution system (2.5 s), $A_{\text {sample }}$ is the cross section area of the sampling line in $\mathrm{m}^{2}, I_{\text {sample }}$ is the length of the sampling line from sample point to the dilution system inlet in meters, and $\dot{Q}_{\text {sample }}$ is the DTT dilution system sample flow in $\mathrm{m}^{3} / \mathrm{s}$. Add $t_{\text {sample }}$ to $t_{\text {dil }}$ to get the total delay time $t_{\text {total: }}$ :

$t_{\text {total }}=t_{\text {sample }}+t_{\text {dil }}$

NOTE: As an example, $t_{\text {total }}$ for a pipe length of $0.5 \mathrm{~m}$ with an internal pipe diameter of $4 \mathrm{~mm}$ and sample flow of $1 \mathrm{~L} / \mathrm{min}$ equals $2.88 \mathrm{~s}$.

Figure 10 shows an example of the time alignment of the measured particle number (blue dotted line) to the time shifted particle number (blue line).

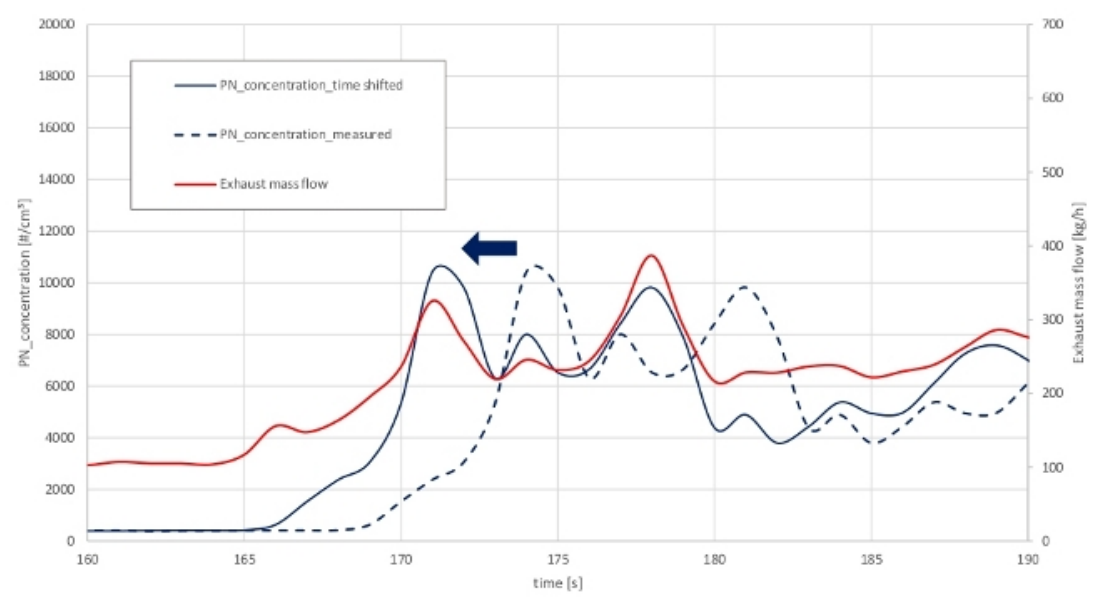

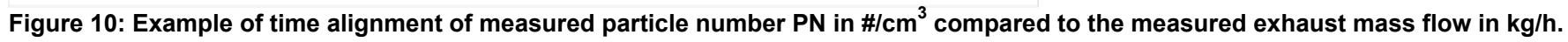
Please click here to view a larger version of this figure.

3. To be able to calculate the particle number in $P N \# / \mathrm{s}$, the exhaust gas volume flow $\dot{V}_{\text {exhaust } n o r m}$ in $\mathrm{cm}^{3} / \mathrm{s}$ must be calculated first according to the following formula: 
$\dot{V}_{\text {echaust }_{\text {mam }}}=\frac{\dot{m}_{\text {edhaust }} * R * T_{\text {morm }}}{p_{\text {norm }}}$

where $\dot{V}_{\text {exhaust_norm }}$ is the exhaust standard volume flow in $\mathrm{m}^{3} / \mathrm{s}, \dot{m}_{\text {exhaust }}$ is the measured exhaust mass flow in $\mathrm{kg} / \mathrm{s}, R$ is the ideal gas constant for air $\left(287.1 \mathrm{~J} / \mathrm{kg}^{*} \mathrm{~K}\right), T_{\text {norm }}$ is the temperature at standard conditions $(273.15 \mathrm{~K})$, and $p_{\text {norm }}$ is the pressure at standard conditions $(101,330 \mathrm{~Pa})$. With this exhaust volume flow at standard conditions the particle number can be calculated by multiplying the $\dot{V}_{\text {exhaust norm }}$ with the dilution ratio $D R$ of the sampling system, the concentration $\mathrm{C}_{\mathrm{PN}}$ measured by the CPCs, and the factor $10^{6}$ (for the conversion from $\mathrm{m}^{3}$ to $\left.\mathrm{cm}^{3}\right)$.

$P N=\dot{V}_{\text {echaust }_{\text {min }}} * c_{P N} * D R * 10^{6}$

4. To correct for particle losses, multiply the particle exhaust flow times the particle number concentration rate with the system particle concentration reduction factor $(P C R F)$ instead of the dilution ratio $D R$. The determination of $P C R F$ is described in the calibration instruction section 1:

$P N_{\text {orr }}=\dot{V}_{\text {exhaust }} * C_{P \mathrm{~N}} * P C R F$

\section{Representative Results}

Calibration Data (Particle Penetration):

Figure 11 shows an exemplary plot of the relative particle penetration of the DTT system as a function of the particle mobility diameter. The corresponding data have been measured and evaluated as described in instruction section 1. The plot shows that the deviations between two measurement points at the same mobility diameter were less than $5 \%$. Deviations larger than $10 \%$ indicate instabilities in the experimental setup. In this case, the calibration had to be repeated with increased warm up stabilization times. Both the warm up time (typically 30 min) and the stabilization time (typically $30 \mathrm{~s}$ ) increased by a factor of 1.5 .

The particles passing through the DTT system were lost due to diffusion and thermophoresis. Thermophoretic losses were caused by a temperature gradient drawing particles towards the walls of the sampling system. This is a particle size independent effect ${ }^{29}$; in contrast, diffusion is highly particle size dependent. A concentration gradient caused a net particle flux towards the walls where particles were lost. The diffusivity rising with lower particle size made this the dominant loss mechanism for particles $\leq 10 \mathrm{~nm}$. The lines in Figure 11 indicating thermophoretic, diffusional, and total losses demonstrate the respective particle size dependencies. For the diffusional losses, this function was used to illustrate the approximate particle size dependency:

$P=\exp \left(\frac{-a}{D\left(d_{p}\right)}\right)$

The penetration $P$ depends on a fit parameter $a$ and the diffusion coefficient $D$ :

$D=\frac{k T C_{c}}{3 \pi \eta d_{p}}$

The diffusion coefficient depends on the Boltzmann constant $k$, the absolute temperature $T$, the viscosity $\eta$, the particle diameter $d_{\mathrm{p}}$, and the Cunningham slip correction factor $C_{c}$, which is a function of the mean free path and the particle diameter ${ }^{29}$.

The data illustrated in Figure 11 resulted in the following mean particle penetration efficiency $P_{\text {mean: }}$ :

$P_{\text {mean }}=\frac{P_{30 \mathrm{~nm}}+P_{50 \mathrm{~nm}}+P_{100 \mathrm{~mm}}}{3}=\frac{0.795+0.825+0.825}{3}=\underline{\underline{0.815}}$

The particle size where the penetration efficiency amounts to $50 \%$ is referred to as $d_{50}$. The $d_{50}$ describes the penetration cutoff characteristic of a system. For the DTT system the $d_{50}$ was $11 \mathrm{~nm}$. The $d_{50}$ is shown in Figure 11. 


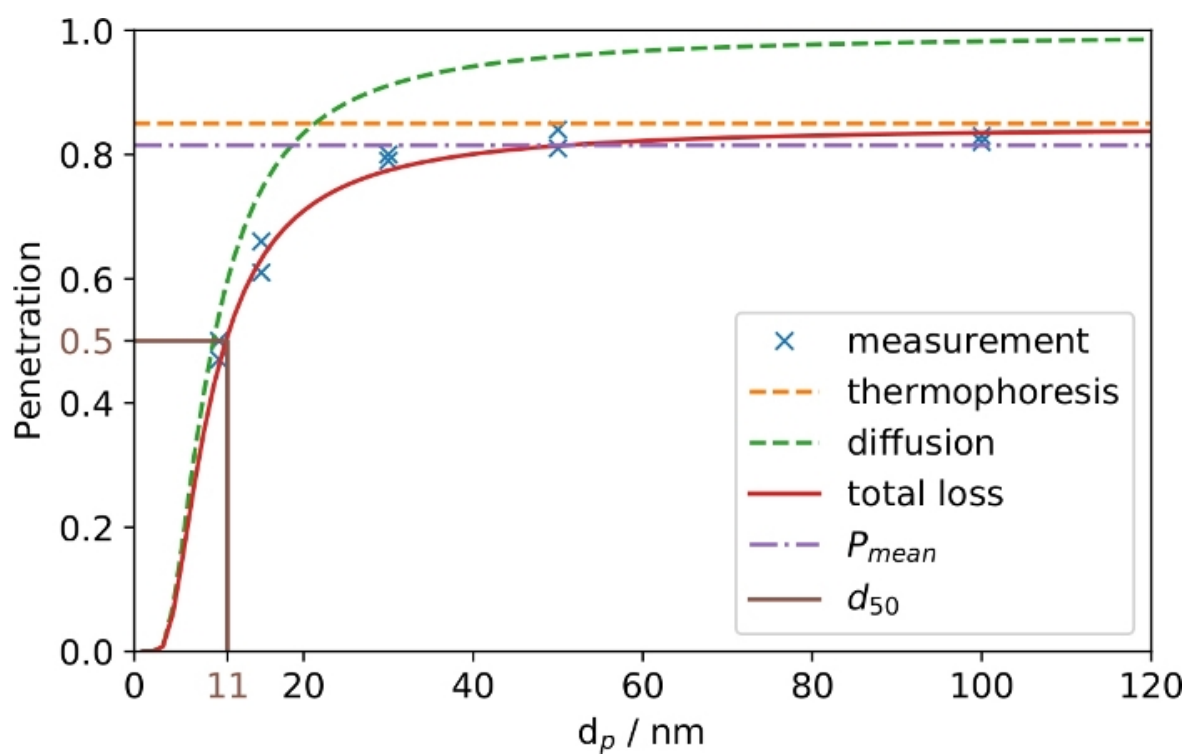

Figure 11: Particle penetration as a function of particle mobility diameter.

Points marked in blue are measurement results. The dashed lines in orange and green indicate the losses associated with thermophoresis and diffusion, respectively. The red line represents the total losses as the sum of diffusional and thermophoretic losses. The dotdashed purple line shows the average particle penetration Pmean as calculated in the calibration measurement instruction section 1 . Please click here to view a larger version of this figure.

\section{Solid Particle Number:}

Figure 12 shows the particle number emission rate over time for the first ten minutes of an RDE measurement drive. The data from the DTT PEMS using a $10 \mathrm{~nm}$ and a $23 \mathrm{~nm} \mathrm{CPC}$ are shown together with data from a commercially available $23 \mathrm{~nm}$ cut point system. The particle emission rates were calculated from the respective particle concentrations multiplied by the exhaust flow rate as described above in the data analysis instruction section 4. The reference instrument (AVL MOVE) relied on a diffusion charger for the particle number concentration measurement. Despite the different sensor principles, the data measured with the DTT PEMS were overall in very good agreement with the data measured by the commercially available PEMS. Sharp downwards pointing spikes in all three signals occurred because the particle measurement devices can report zero particle concentrations temporarily and zeros cannot be displayed in logarithmic plots. The particle emissions measured with the $10 \mathrm{~nm}$ CPC were very close to the emissions measured with the $23 \mathrm{~nm}$ CPC for the majority of the time period shown in Figure 12. However, right at the beginning between $10 \mathrm{~s}$ and $25 \mathrm{~s}$ there was an occurrence of significant $<23 \mathrm{~nm}$ particle emission. The DTT $10 \mathrm{~nm}$ signal was significantly higher than the $23 \mathrm{~nm}$ signal of the DTT system and the AVL MOVE. In this case, >50\% of the total number of particles emitted were between $10 \mathrm{~nm}$ and $23 \mathrm{~nm}$. Cold start dynamic processes in non-thermal equilibrium can cause particle size distributions to differ from emissions from a hot vehicle ${ }^{30}$. The discussion of these complex processes is beyond the scope of this work. Further information on this topic can be found in the literature ${ }^{31,32,33}$.
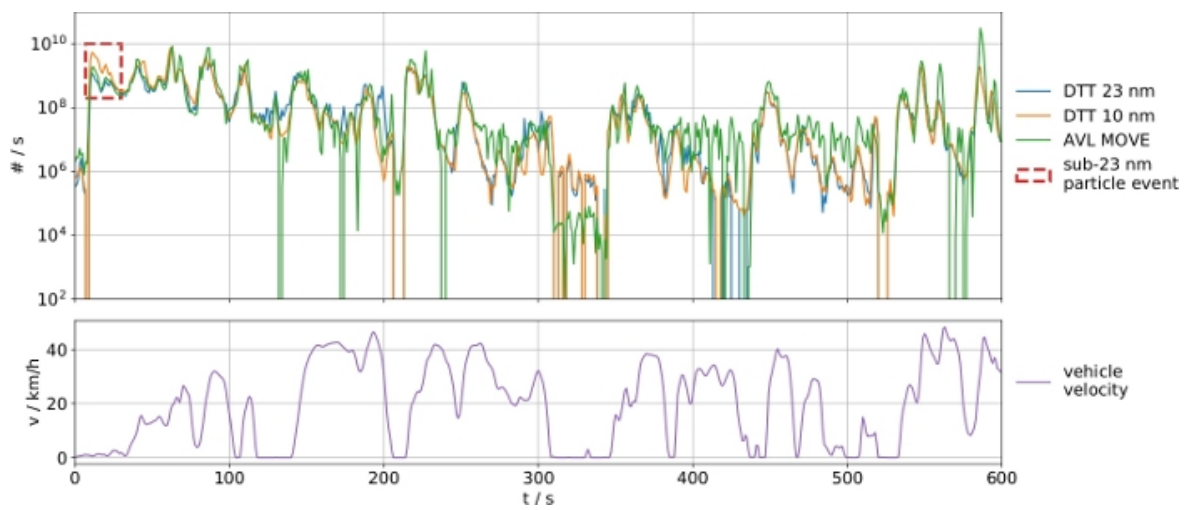

Figure 12: The upper part of the figure shows the particle number emission rate over time for the first 10 mins of an RDE measurement drive.

Data measured with the DTT PEMS using $10 \mathrm{~nm}$ and $23 \mathrm{~nm}$ CPC and a commercially available $23 \mathrm{~nm}$ cut point system (AVL MOVE) are used as a reference. The lower part of the figure shows the velocity of the vehicle. Please click here to view a larger version of this figure.

\section{Discussion}

This work presents the DTT sampling system and its application as a portable emission measurement system. The system was designed and constructed within the EU Horizon 2020 project DTT to enable particle number emission measurements below the current legislative particle size limit of $23 \mathrm{~nm}$. The system's versatility enables the assessment of the regulated solid particle number emissions as well as total particle 
emissions and studies on secondary aerosols. To interpret measurement results accurately, a calibration procedure is necessary with the DTT system. This is to evaluate the relative particle penetration for different particle sizes, to be able to calculate a correction factor that accounts for the particle losses. It is critical to provide sufficient warm up time for the sampling system itself and the rest of the experimental setup to reach thermal equilibrium and achieve accurate calibration measurement results.

The application of the DTT system for the measurement of solid particle number emissions with a lower particle size cutoff of $23 \mathrm{~nm}$ (current regulation) and $10 \mathrm{~nm}$ (experimental) is described. To be able to assess particle number emissions of a vehicle it is necessary to determine the particle number concentration and the exhaust mass flow rate. The DTT system covers the particle number concentration measurement. The exhaust mass flow is measured using an exhaust flow meter (EFM). It is critical to install the EFM according to the manufacturer's instructions. Erroneous measurements of the exhaust flow rate directly affect the deduced emission rates. When processing the measured data, it is important to perform an accurate time alignment of the particle concentration data and the exhaust flow data. This is necessary because the emission rate is the exhaust flow rate multiplied by the particle number concentration. If the two signals are not aligned correctly, the emissions over the whole drive can significantly deviate from the real emissions.

The DTT system is not a commercial device but a versatile research tool. It is used to investigate unregulated vehicle emissions as opposed to performing certification measurements validating compliance with current regulations. The high versatility comes at the cost of increased energy and dilution air consumption. When using the system for mobile measurements, the weight added to the vehicle due to the battery ( 30 $\mathrm{kg}$ ) and gas bottle $(20 \mathrm{~kg})$ to cover the energy and air consumption of the system must be kept in mind. The total weight added to the car when measuring the PN emissions with the DTT system is approximately $80 \mathrm{~kg}$, which is comparable to another person being transported in the vehicle. The added weight can lead to slightly increased emissions, especially if the drive includes a great deal of acceleration and/or hills.

The DTT system can be used to investigate the unregulated $<23 \mathrm{~nm}$ particle number exhaust emissions. Both solid and total particle number emissions can be measured. Furthermore, it can be a useful tool to study the complex field of secondary aerosol formation. Another possible application of the system is the measurement of automotive brake wear particles. A significant fraction of the particles emitted during braking events can be smaller than $30 \mathrm{~nm}^{34}$. With a $d_{50}$ of approximately $11 \mathrm{~nm}$, the DTT system is suitable for studying these emissions. Although it is known that non-exhaust emissions contribute almost equally to traffic-related $\mathrm{PM}_{10}$ emissions ${ }^{35}$, non-exhaust particle emissions are still unregulated. This is due to the complex and seldom reproducible process of particle generation, making it very difficult to set regulatory actions. Furthermore, the chemical composition and the related toxicity of organic brake wear particles is still widely unknown ${ }^{35}$.

The DTT system is a useful tool to improve our understanding of both exhaust and non-exhaust traffic-related particle emissions.

\section{Disclosures}

The authors have nothing to disclose.

\section{Acknowledgments}

This work is conducted in the framework of the H2020 project DownToTen. This project has received funding from the European Union's Horizon 2020 research and innovation programme under grant agreement Nr. 724085.

\section{References}

1. Dunne, M. GRPE Particulate Measurement Programme (PMP). 7th ETH-Conference on Combustion Generated Nanoparticles. (2003).

2. Sydbom, A. et al. Health effects of diesel exhaust emissions. European Respiratory Journal. 17 (4), 733-746 (2001).

3. Vehicle Regulations - Transport - UNECE. <https://www.unece.org/trans/main/welcwp29.html>. (2020).

4. Andersson, J., Wedekind, B. DETR / SMMT / CONCAWE Particulate Research Programme 1998-2001 SUMMARY REPORT. (2001).

5. Samaras, Z. et al. Publication data form 1. Framework Programme European Commission-DG TrEn, 5 th Framework Programme Competitive and Sustainable Growth Sustainable Mobility and Intermodality 2. Contract No. at <http://vergina.eng.auth.gr/mech/Lat/ particulates/private/index.htm>. (2005).

6. Andersson, J., Giechaskiel, B., Muñoz-Bueno, R., Sandbach, E., Dilara, P. Particle Measurement Programme (PMP) Light-duty Interlaboratory Correlation Exercise (ILCE_LD) Final Report Institute for Environment and Sustainability 2007 EUR 22775 EN. at <http:// publications.jrc.ec.europa.eu/repository/bitstream/111111111/429/2/7386 - PMP_LD_final.pdf>. (2007).

7. Rönkkö, T. et al. Effects of gaseous sulphuric acid on diesel exhaust nanoparticle formation and characteristics. Environmental Science and Technology. 47 (20), 11882-11889 (2013).

8. Liati, A., Dimopoulos Eggenschwiler, P. Characterization of particulate matter deposited in diesel particulate filters: Visual and analytical approach in macro-, micro- and nano-scales. Combustion and Flame. 157 (9), 1658-1670 (2010).

9. Liati, A., Schreiber, D., Arroyo Rojas Dasilva, Y., Dimopoulos Eggenschwiler, P. Ultrafine particle emissions from modern Gasoline and Diesel vehicles: An electron microscopic perspective. Environmental Pollution. 239, 661-669 (2018).

10. Kittelson, D. B. Recent Measurements of Nanoparticle Emissions from Engines. Current Research on Diesel Exhaust Particles Japan Association of Aerosol Science and Technology. 5 (2001).

11. Bruno, T. J., Ott, L. S., Smith, B. L. Composition-Explicit Distillation Curves of Waste Lubricant Oils and Resourced Crude Oil: A Diagnostic for Re-Refining and Evaluation. American Journal of Environmental Sciences. 6 (6), 523-534 (2010).

12. Giechaskiel, B., Vanhanen, J., Väkevä, M., Martini, G. Investigation of vehicle exhaust sub-23 nm particle emissions. Aerosol Science and Technology. 51 (5), 626-641 (2017).

13. Andersson, J. Call: H2020-GV-2016-2017: DownToTen. 48th PMP Update. at <https://wiki.unece.org/download/attachments/73924923/ PMP-48-10 DTT_Update_Nov_2018.pdf> (2018).

14. Andersson, J. PMP 50th Session - Transport - Vehicle Regulations - UNECE Wiki. at <https://wiki.unece.org/display/trans/PMP+50th + Session>. (2019). 
15. Martikainen, S. et al. Dependence of Dilution Performance of a Prototype Setup for Sampling Non- volatile Engine Exhaust Particles down to ten Nanometer in Diameter on Pressure Variations in Sample Line. 22nd ETH Conference on Combustion Generated Particles. 1, at <http:// www.nanoparticles.ch/2018_ETH-NPC-22/2018_ETH-NPC-22_book_of_abstracts_posters.pdf> (2018).

16. Landl, L., Vuckovic, T., Hausberger, S. PEMS accuracies under harsh environmental conditions. 23rd Transport and Air Pollution Conference, Thessaloniki 2019. at <https://www.tapconference.org/assets/files/previous-conferences/proceedings/2019_Proceedings.zip> (2019).

17. Karjalainen, P. et al. Time-resolved characterization of primary particle emissions and secondary particle formation from a modern gasoline passenger car. Atmospheric Chemistry and Physics. 16 (13), 8559-8570 (2016).

18. Mikkanen, P., Moisio, M., Keskinen, J., Ristimäki, J., Marjamäki, M. Sampling method for particle measurements of vehicle exhaust. SAE Mobilus. 2001-01-0219 (2001).

19. Giechaskiel, B. et al. Review of motor vehicle particulate emissions sampling and measurement: From smoke and filter mass to particle number. Journal of Aerosol Science. 67, 48-86 (2014).

20. EC Commission Regulation (EU) 2017/1154. Official Journal of the European Union. at <https://eur-lex.europa.eu/eli/reg/2017/1154/oj> (2017).

21. Mamakos, A., Khalek, I., Giannelli, R., Spears, M. Characterization of combustion aerosol produced by a mini-CAST and treated in a catalytic stripper. Aerosol Science and Technology. 47 (8), 927-936 (2013).

22. Jing, L. Standard Combustion Aerosol Generator (SCAG) for Calibration Purposes. Atmospheric Environment. 27 (8), $1271-1275$ (1999).

23. Moore, R. H. et al. Mapping the operation of the miniature combustion aerosol standard (Mini-CAST) soot generator. Aerosol Science and Technology. 48 (5), 467-479 (2014).

24. Giechaskiel, B. et al. Implementation of portable emissions measurement systems (PEMS) for the real-driving emissions (RDE) regulation in Europe. Journal of Visualized Experiments. (118), 54753 (2016).

25. EC Commission Regulation (EU) 2017/1151. Official Journal of the European Union. (692), 1-643, at <https://eur-lex.europa.eu/eli/ reg/2017/1151/oj> (2017).

26. EC REGULATION (EC) No 715/2007 OF THE EUROPEAN PARLIAMENT AND OF THE COUNCIL. Official journal of the European Union. at <https://eur-lex.europa.eu/Legal-content/EN/ALL/?uri=CELEX:32007R0715> (2007).

27. EC DIRECTIVE 2007/46/EC OF THE EUROPEAN PARLIAMENT AND OF THE COUNCIL. Official journal of the European Union. at <https:// eur-lex.europa.eu/Legal-content/EN/ALL/?uri=CELEX:32007L0046> (2007).

28. EC Commission Regulation 2790/99. Official Journal of the European Communities. at <https://eur-lex.europa.eu/Legal-content/EN/TXT/? uri=CELEX\%3A31999R2790> (1999).

29. Hinds, W.C. Aerosol technology: properties, behavior, and measurement of airborne particles. John Wiley \& Sons. (2012).

30. Badshah, H., Kittelson, D., Northrop, W. Particle Emissions from Light-Duty Vehicles during Cold-Cold Start. SAE International Journal of Engines. 9 (3), 1775-1785 (2016).

31. Andersson, J. et al. First results of vehicle technology effects on sub-23nm exhaust particle number emissions using the DownTo10 sampling and measurement system. 22nd ETH-Conference on Combustion Generated Nanoparticles,. at <https://www.nanoparticles.ch/ archive/2018_Andersson_PR.pdf> (2018).

32. Giechaskiel, B., Manfredi, U., Martini, G. Engine exhaust solid sub-23 nm particles: I. Literature survey. SAE International Journal of Fuels and Lubricants. 7 (2014-01-2834), 950-964 (2014).

33. Weiss, M., et al. Including cold-start emissions in the Real-Driving Emissions (RDE) test procedure. Publications Office of the European Union. https://op.europa.eu/en/publication-detail/-/publication/66874f0c-fd85-11e6-8a35-01aa75ed71a1/language-en/format-PDF/ source-120155396, (2017).

34. Mathissen, M., Scheer, V., Vogt, R., Benter, T. Investigation on the potential generation of ultrafine particles from the tire-road interface. Atmospheric Environment. 45 (34), 6172-6179 (2011).

35. Grigoratos, T., Martini, G. Brake wear particle emissions: a review. Environmental Science and Pollution Research. 22 (4), $2491-2504$ (2015). 